RESEARCH NOTE

\section{Susceptibility of Aedes scapularis (Rondani, 1848) to Dirofilaria immitis (Leidy, 1856), an Emerging Zoonosis}

\section{Fabiane Carvalho de Macêdo, Norma Labarthe, Ricardo Lourenço-de- Oliveira $^{+}$}

Laboratório de Transmissores de Hematozoários, Departamento de Entomologia, Instituto Oswaldo Cruz, Av. Brasil 4365, 21045-900 Rio de Janeiro, RJ, Brasil

Key words: Aedes scapularis - Dirofilaria immitis heartworm - vectors of canine heartworm

Dirofilaria immitis is the causative agent of canine heartworm, a well known parasitic cardiopulmonary disease of dogs and cats, that can also affect man (NB Robinson et al. 1977 J Thor Cardiov Surg 74: 403-408). When this nematode infects man the disease is difficult to diagnose, but even so there are more than 200 cases of human pulmonary dirofilariasis reported throughout the world (CAR Schneider et al. 1986 Acta Oncol Bras 6: 125-130, R Rodrigues-Silva et al. 1995 Rev Inst Med Trop São Paulo 37: 523-530).

Although the principal mosquito vectors of $D$. immitis have not been determined in all areas, it has been shown that, depending on the geographic region, the nematode can be transmitted by mosquito species belonging to the genera Culex, Aedes, Anopheles, Mansonia, Psorophora and Coquillettidia (KW Ludlam et al. 1970 JAVMA 157: 1354-1359). Investigations to elucidate the potential of some mosquito species as vectors of canine heartworm in southeastern Brazil were prompted by reports of prevalences in dogs, as high as $52.5 \%$ at the seashore and by the threat of human infections (N Labarthe et al. 1997 Mem Inst Oswaldo Cruz 92: 47-51). Natural infections of one Ae. scapularis and one Ae. taeniorhynchus

${ }^{+}$Corresponding author. Fax: +55-21-290.9339

Received 23 January 1998

Accepted 17 April 1998
(Wiedemann, 1821) with presumed D. immitis larvae in their Malpighian tubules were reported previously in a coastal lowland area in the city of Rio de Janeiro (R Lourenço-de-Oliveira \& LM Deane 1995 Mem Inst Oswaldo Cruz 90: 387-388).

Both mosquito species were later found to be among the most abundant, besides being found harboring filariae, at a canine heartworm focus of similar landscape in the municipality of Niterói, State of Rio de Janeiro (N Labarthe et al. 1998 Mem Inst Oswaldo Cruz 93: 425-432). Ae. taeniorhynchus has been considered the primary vector of D. immitis in areas of the United States (DM Sauerman \& JK Nayar 1983 Mosq News 43: 222-225). However, the vectorial competence of Ae. scapularis for D. immitis has never been evaluated. The present study is aimed to evaluate this species as a vector under experimental conditions.

Females of Ae. scapularis were captured on human-bait in Itacoatiara, Guaraí and Pedra de Guaratiba, coastal lowlands in the State of Rio de Janeiro. They were bloodfed and subsequently laid eggs on wet filter paper. The eggs were kept wet for 10-15 days and subsequently stored dry in desiccators. Eggs were hatched by submerging them in water. Larvae were fed with a commercial fish food (TetraMin, Tetrawerke Co.). A susceptible strain of Ae. aegypti (Linnaeus, 1762) was used as control. It was an Ae. aegypti colony started ten years ago from wild females caught in Rio de Janeiro, whose larvae were reared in the same conditions of those of Ae. scapularis. Seven-day old females of both species were simultaneously provided with fresh dog blood containing 60-70 microfilariae $/ 20 \mu \mathrm{l}$ in an artificial feeding apparatus (LC Rutledge et al. 1964 Mosq News 24: 407-419). The females of both species were similar in size and it was supposed that they took similar amounts of infected blood. After the infective blood meal, mosquitoes were provided a solution of $10 \%$ dextrose and kept at $24-26^{\circ} \mathrm{C}$ and $65-70 \%$ relative humidity. Mosquito dissections were performed weekly for three weeks after the infective blood meal, and mortality rates were recorded. After chloroform anesthesia, the mosquitoes were dissected and the head, mouthparts, midgut, Malpighian tubules, and thorax were thoroughly examined in $0.89 \% \mathrm{NaCl}$ for worms, and the number at different locations counted. The number of larvae/location was statistically analyzed by median scores and the proportion of infected/dissected mosquitoes analyzed by chi square.

The results of dissections of both Ae. scapularis (Fig.) and Ae. aegypti from 9 to 21 days post-infective blood meal are presented in the Table. One hundred Ae. aegypti and 210 Ae. scapularis were fed with infected blood. The mortality rate was high 
in both species: $71 \%$ Ae aegypti and $79 \%$ Ae. scapularis. Since there were no comparisons with controls fed uninfected blood, these mortality rates may not be attributable to nematode burden.

The larval number in the Malpighian tubules/ infected mosquito was nearly the same for both mosquito species $(\mathrm{p}=0.4561)$, while at two and three weeks post-infection a larger proportion of larvae reached the infective stage in the head and proboscis of Ae. aegypti than in Ae. scapularis ( $\mathrm{p}=0.0833$, Table). Larval development in Ae. scapularis appears to be slower than in Ae. aegypti.

The mean number of larvae per infected mosquito was 8.4 in Ae. aegypti and 6.9 in Ae. scapularis. A larger proportion of mosquitoes was found infected in Ae. scapularis (79.5\%) than in
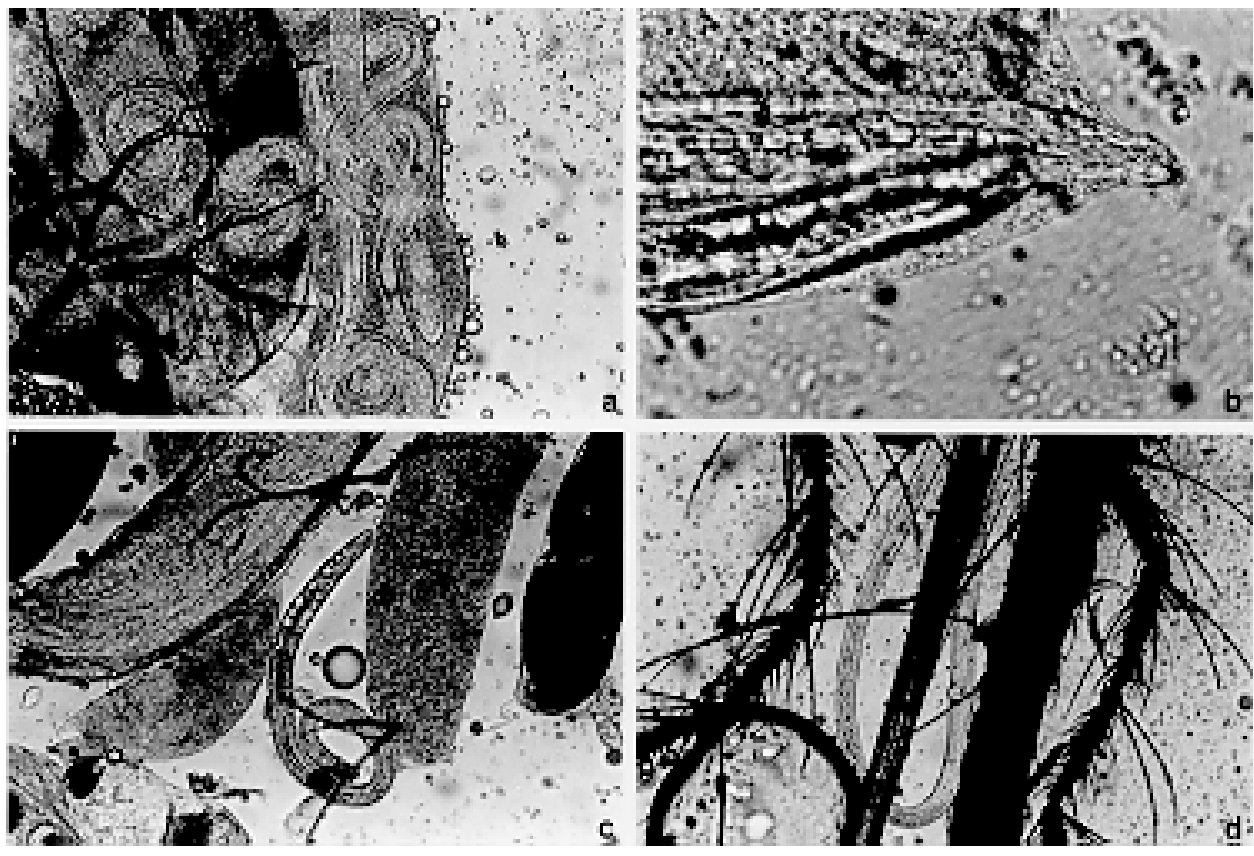

Dirofilaria immitis larvae developing in Aedes scapularis under experimental conditions. a: larvae $\left(\mathrm{L}_{2}\right.$ and $\left.\mathrm{L}_{3}\right)$ in $\mathrm{Malpighian}$ tubules (200x); b: third stage larva trying to leave the distal tip of the Malpighian tubule (400x); c: free $\mathrm{L}_{3}$ larva in the hemolymph, just after leaving the Malpighian tubule (200x); d: infective larva at the mouthparts (200x).

TABLE

Aedes scapularis and Ae. aegypti artificially infected by Dirofilaria immitis

\begin{tabular}{|c|c|c|c|c|c|c|}
\hline & Ae. & laris & & & egypti & \\
\hline & $\begin{array}{l}\text { No. infected/ } \\
\text { dissected }\end{array}$ & Local & No. larvae & $\begin{array}{l}\text { No. infected/ } \\
\text { dissected }\end{array}$ & Local & No. larvae \\
\hline 9 days PI & $1 / 1$ & MT & 15 & $1 / 1$ & MT & 17 \\
\hline 2 weeks PI & $22 / 26$ & $\begin{array}{l}\mathrm{MT} \\
\mathrm{HD} / \mathrm{PB}\end{array}$ & $\begin{array}{r}167 \\
05\end{array}$ & $4 / 21$ & $\begin{array}{l}\text { MT } \\
\text { TX } \\
\text { HD/PB }\end{array}$ & $\begin{array}{l}13 \\
07 \\
09\end{array}$ \\
\hline 3 weeks PI & $12 / 17$ & $\begin{array}{l}\text { MT } \\
\text { TX } \\
\text { HD/PB }\end{array}$ & $\begin{array}{l}43 \\
01 \\
11\end{array}$ & $3 / 7$ & $\begin{array}{l}\mathrm{MT} / \mathrm{AB} \\
\mathrm{HD} / \mathrm{PB}\end{array}$ & $\begin{array}{l}03 \\
18\end{array}$ \\
\hline Total & $35 / 44$ & $\begin{array}{l}\text { MT } \\
\text { TX } \\
\text { HD/PB }\end{array}$ & $\begin{array}{r}225^{a} \\
01 \\
16\end{array}$ & $8 / 29$ & $\begin{array}{l}\text { MT/AB } \\
\text { TX } \\
\text { HD/PB }\end{array}$ & $\begin{array}{l}33^{b} \\
07 \\
27\end{array}$ \\
\hline
\end{tabular}

PI: post infection; MT: Malpighian tubules; TX: thorax; HD: head; PB: proboscis; $a$ : $28 \%$ of the larvae were melanized; $b$ : no melanization was observed. 
Ae. aegypti $(27.6 \%)(\mathrm{p}<0.0001$, Table). Although mosquito mortality after infection was high in both species, those figures suggest that infected $A e$. scapularis may show a higher capacity to support the infection than Ae. aegypti, perhaps arresting some larvae development (L Kartman 1953 Exp Parasitol 2: 27-78, BM Christensen 1981 Trans $R$ Soc Trop Med 75: 439-443). Accordingly, only some larvae complete their cycle in Ae. scapularis and so, by means of controlling such infection, this mosquito species enhances its own survival. Dogs frequently demonstrate high microfilaremia (JB Lok et al. $1988 \mathrm{~J}$ Helminthal 62: 175-180) and mosquitoes may die after ingesting blood with a high density of microfilariae (DM Sauerman 1980 Mechanisms in Mosquitoes Responsible for Variation in Susceptibility to Infection by D. immitis
(Leidy), Etiologic Agent of Canine Heartworm Disease, PhD Thesis, University of Florida, 168 pp.). To be efficient vectors of $D$. immitis, mosquitoes must limit the number of developing parasites (Christensen 1981 loc. cit.). Ae. scapularis mosquitoes apparently controlled their larval burden (28\% larval melanization, Table) but did not suppress their maturation and migration of non-melanized larvae to the head and proboscis. This provides additional evidence that Ae. scapularis is a suitable vector for $D$. immitis.

Acknowledgments: to Maria Lúcia Serrão and Dinair Couto Lima for the assistance in rearing and dissecting the mosquitoes. To Núbia Karla de Oliveira Almeida for performing the statistical analysis. To LP Lounibos for the critical reading of the manuscript. To Heloisa MN Dinis for assistance with images. 
